\title{
Some aspects of the biology of the North American ostracod Sarsiella zostericola Cushman in the vicinity of a British power station
}

\author{
R. N. BAMBER \\ C.E.R.L. Marine Biology Unit, C.E.G.B., Fawley, Southampton, SO4 1TW
}

\begin{abstract}
A population of the North American myodocopid ostracod Sarseilla zostericola Cushman has become established in the River Medway, Kent, in the vicinity of the cooling water discharge from Kingsnorth Power Station, though not living in the thermally stressed regions of the discharge environment. The species is assumed to have been introduced with North American oysters, but is not an example of an 'exotic' species surviving in association with the heated discharge. The Kingsnorth individuals are larger and more fecund than those of studied North American populations. The breeding biology, life history and sex ratio are discussed. It is suggested that the intolerance of S.zostericola to the conditions of the thermally stressed discharge canal is associated with shell physiology.
\end{abstract}

\section{INTRODUCTION}

Kingsnorth Power Station is situated on the River Medway, Kent; it has an extensive cooling water discharge system comprising a $4 \mathrm{~km}$ creek, effectively canalising the effluent water at low tide. A comprehensive study of the sublittoral benthic community of this system (Bamber \& Spencer, 1984) showed that half of the species resident at a control site were sensitive to the temperature regime of the discharge canal, and absent from that community. This suite of thermally sensitive species was characterised by most of the available molluses and the myodocopid ostracod Sarsiella zostericola Cushman, 1906.

S. zostericola (Fig. 1) is a North American species, first reported in British waters by Kornicker (1975) from numerous specimens collected by Dr. Eric Robinson in the Blackwater Estuary, Essex, in 1967 and 1968. These had evidently been introduced with the American oyster Crassostrea virginica (Gmelin), young of which had been imported and relaid at various sites in the Thames and associated estuaries up until 1940, to be grown on for the London market. Among the other sites of $C$. virginica introduction shown by Kornicker (1975, Fig. 3) is one at Sheerness at the mouth of the River Medway, some $7.5 \mathrm{~km}$ downstream of Kingsnorth.

An understanding of the life history and biology of the sensitive species identified at Kingsnorth should enable some generalisations about animals susceptible to the temperature conditions of power station cooling water discharges. Being an immigrant species, $S$. zostericola is also of interest in the light of the often conjectured hypothesis of 'exotic' species occurring in association with power station discharges (e.g. Langford, 1983, p. 141). Unfortunately, knowledge of the biology of $S$. zostericola is limited (see Jones, 1961; Kornicker, 1967). Fenwick (1984) points out the lack of life history and reproductive studies on ostracods of the Order Myodocopida, despite their importance as members of marine benthic communities.

The $S$. zostericola specimens from Kingsnorth have been studied to supplement the preliminary biological information reported by Kornicker (1967), and to compare aspects of the biology of this species in Britain with the data on North American populations. Its response to the power station discharge is examined.

\section{METHODS}

The sampling techniques, sample site and techniques of measuring environmental characteristics are described in Bamber \& Spencer (1984). S. zostericola specimens were collected from monthly grab samples from Station DC4, on the River Medway Estuary $\left(51^{\circ}\right.$ $24.95^{\prime} \mathrm{N} 0^{\circ} 38.64^{\prime} \mathrm{E}$ ), for most months from May, 1980 to September, 1981. These samples were washed through a $0.5 \mathrm{~mm}$ mesh sieve, being taken for total macrofaunal analysis as part of the larger study.

The length and height of each $S$. zostericola specimen (as defined in Fig. 1b) were measured under the microscope at $\times 50$ magnification, using a curtain micrometer eyepiece; though the length as defined here is not identical to that used by Kornicker (1967), comparisons of the two techniques for 20 individuals over a range of sizes showed the results to be not significantly different. Inter-instar growth factors were calculated as the length of a given instar expressed as a proportion of the length of the previous instar. Adult males and females were distinguished by their characteristic shell morphology. In selected samples of earlier 
instars, sex was determined by the development of the 7 th limb (rudimentary or absent in males) and the endopodite of the 2nd antenna (1-segmented in females, 2- or 3-segmented in males of instar III or older). For each brooding female, the number of embryos in the brood was counted and the length (maximum linear dimension) of five randomly selected embryos was measured.

\section{RESULTS}

The temperature regime at the sample site over the two years of sampling is shown in Fig. 2, based on thermistor measurements of the mud surface in the grab samples. The sediment had a median diameter of $10 \mu \mathrm{m}$, with a silt content of $76.76 \pm 8.62 \%$ (from 11 samples over the two years). Seabed salinity ranged from $26-31 \%$, and the depth was $-2 \mathrm{~m}$ C.D.

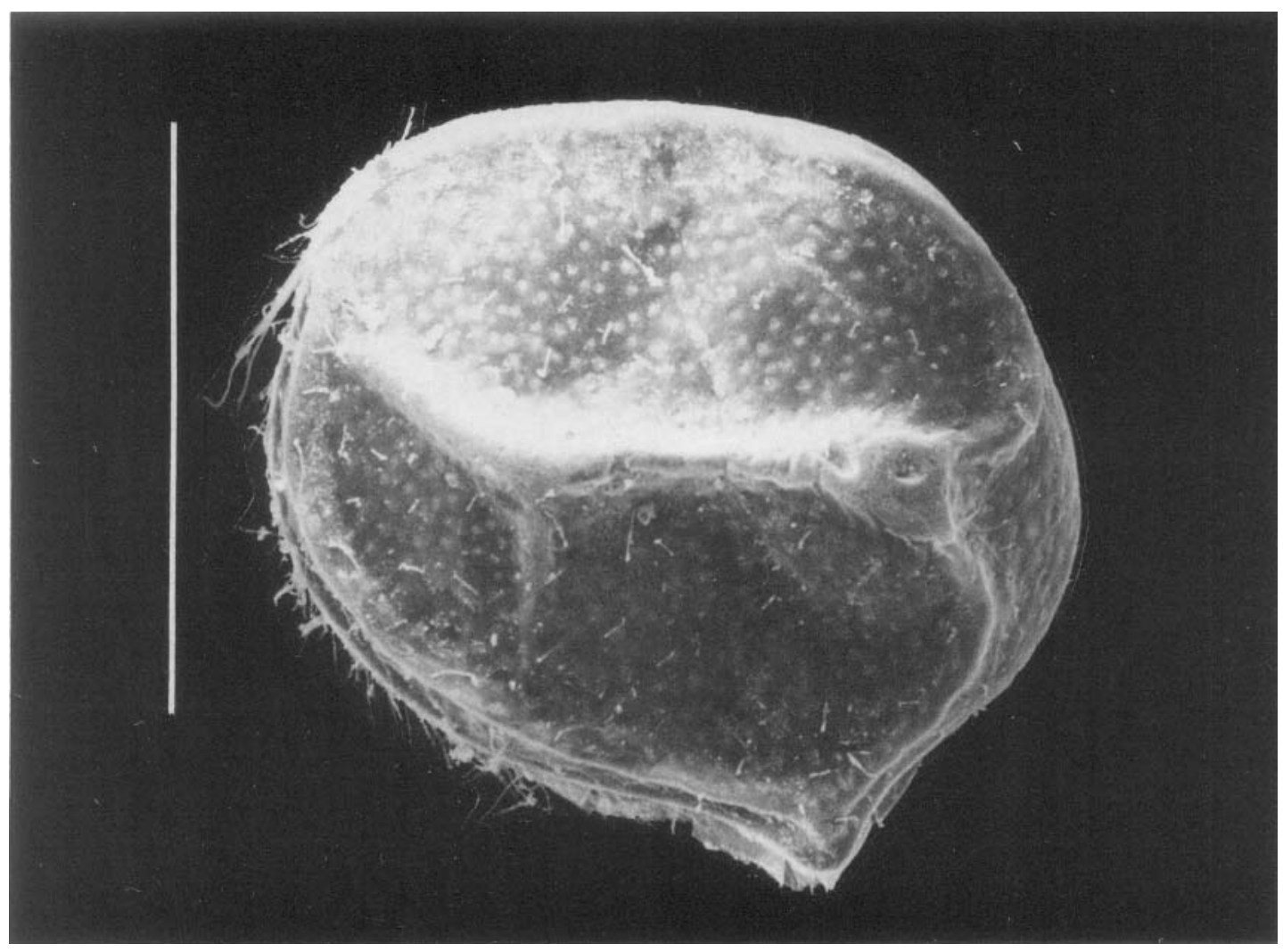

A

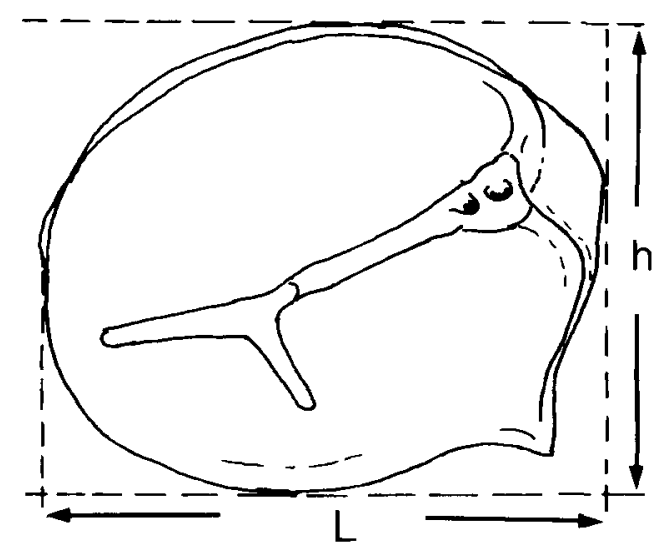

B

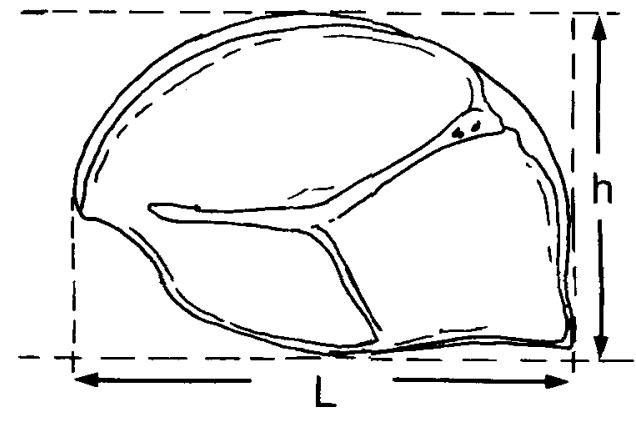

C

Fig. 1. A, female Sarsiella zostericola from Kingsnorth (National Museum of Wales accession no. Z-1986.3.1), lateral, anterior to the left, scale interval $=1 \mathrm{~mm} ; \mathrm{B}$, female and $\mathrm{C}$, male, diagrammatic, showing dimensions measured: $L=$ length, $h=$ height. 


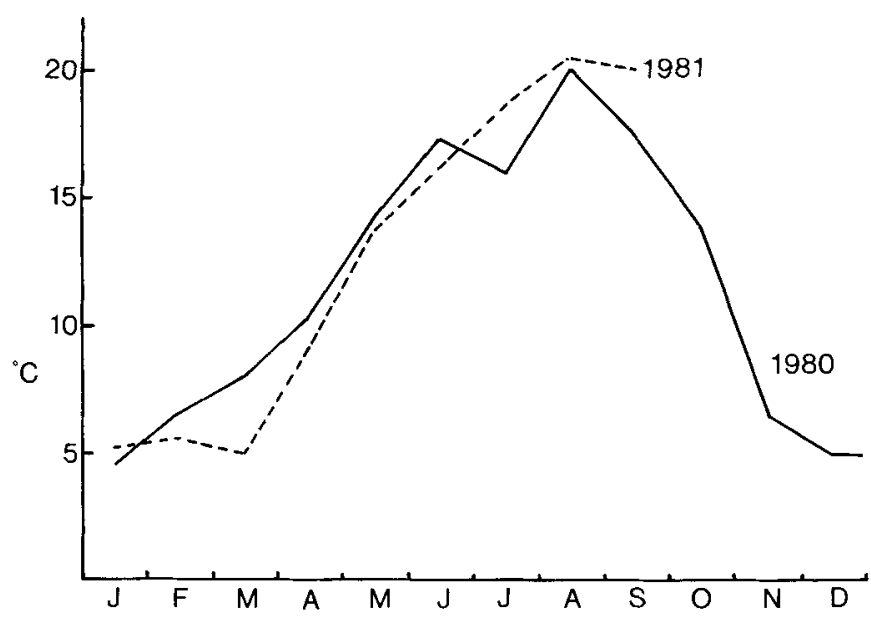

Fig. 2. Seabed temperatures at the sample site, from monthly data for 1980 and 1981.

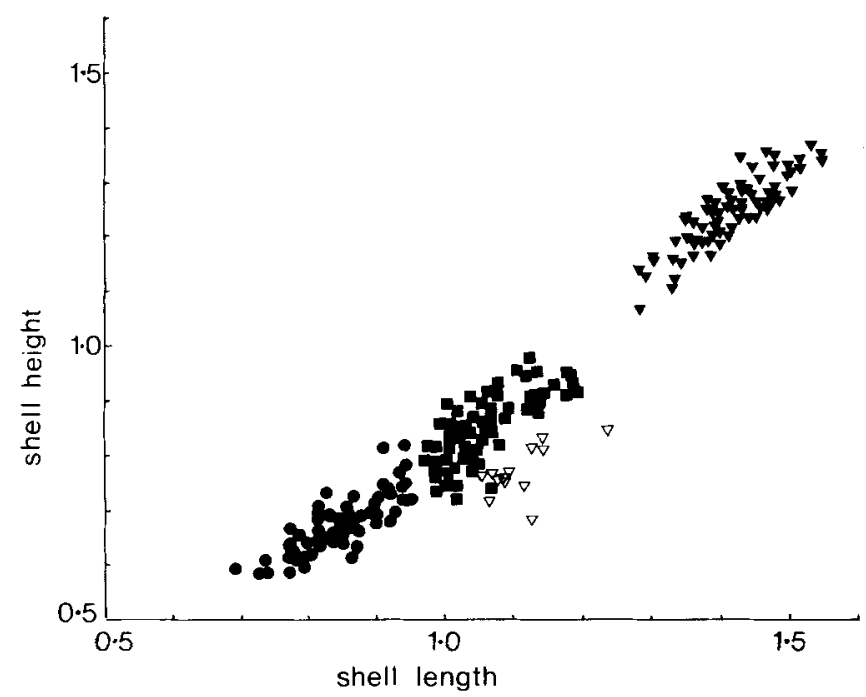

Fig. 3. Shell length plotted against shell height $(\mathrm{mm})$ for Kingsnorth $S$. zostericola specimens; circles instar IV, squares - instar V, filled triangles - adult females, open triangles - adult males.
The length and shell height of each specimen are plotted as Fig. 3, and demonstrate the presence of three instars (including adults) in the material: specimens younger than instar IV were evidently not retained in the $0.5 \mathrm{~mm}$ mesh sieve. The mean sizes for each instar are given in Table 1, together with growth factors for each moult, and the equivalent data for Kornicker's (1967) North American specimens for comparison. The Kingsnorth specimens are significantly larger, such that Kornicker's mean values for each instar fall below the minimum values of the size range for that instar at Kingsnorth (e.g. adult females $1.29-1.56 \mathrm{~mm}$ ). The growth factors are similar for the two sets of data, however, and the mean embryo size for Kingsnorth, from 205 embryos, is lower than that quoted by Kornicker for Massachusetts (sample size $=3$ ?).

Numbers of individuals in the samples were erratic, ranging from zero (August 1980) to 1110 individuals. $\mathrm{m}^{-2}$ (February 1980), suggesting a patchy distribution. These data are consistent with that of samples reported in Kornicker (1967) from California, Texas and Massachusetts.

The population structure, expressed as size class frequency, is shown as Fig. 4, for each month of the year. Since the environmental characteristics were seasonally consistent at the sample site for 1980 and 1981, the monthly data have been amalgamated for the two years of the study to emphasise any population trends. These data indicate an annual life cycle. Adult males appear in the population in April, and brooding females in May; adult males are never common, and numbers decline through the summer, the latest being recorded in October. The peak of female brooding is in July ( $85 \%$ of adult females), and brooding ceases by November. Recruitment of instar IV and V individuals is apparent in the samples from October. While these earliest recruits overwinter as adults, most of the population overwinters as juvenile stages, and these instars are the major proportion of the population from January to May, when they become the breeding adults.

Sex ratios (m:f) for instars IV (22:32) and V (22:17) are not significantly different from $1: 1\left(X^{2}, p>0.1\right)$. The adult sex ratio is less clear owing to the brevity of

Table 1. Mean sizes $(\mathrm{mm})$ and growth factors at each moult for each instar of Sarsiella zostericola at Kingsnorth (adult males separate), with Kornicker's (1967) American data for comparison (in parentheses).

\begin{tabular}{|c|c|c|c|c|}
\hline Instar & Mean length & Growth factor & Mean height & Growth factor \\
\hline IV & $0.86(0.69)$ & $1.24(1.33)$ & $0.66(0.59)$ & \\
\hline V & $1.07(0.92)$ & $1.34(1.34)$ & $0.83(0.79)$ & $1.49(1.41)$ \\
\hline Adult $q$ & $1.43(1.24)$ & & $1.24(1.11)$ & \\
\hline Adult $\sigma^{\pi}$ & $1.13(0.99)$ & & $0.77(0.64)$ & \\
\hline Embryo & $0.24(0.32)$ & & & \\
\hline
\end{tabular}




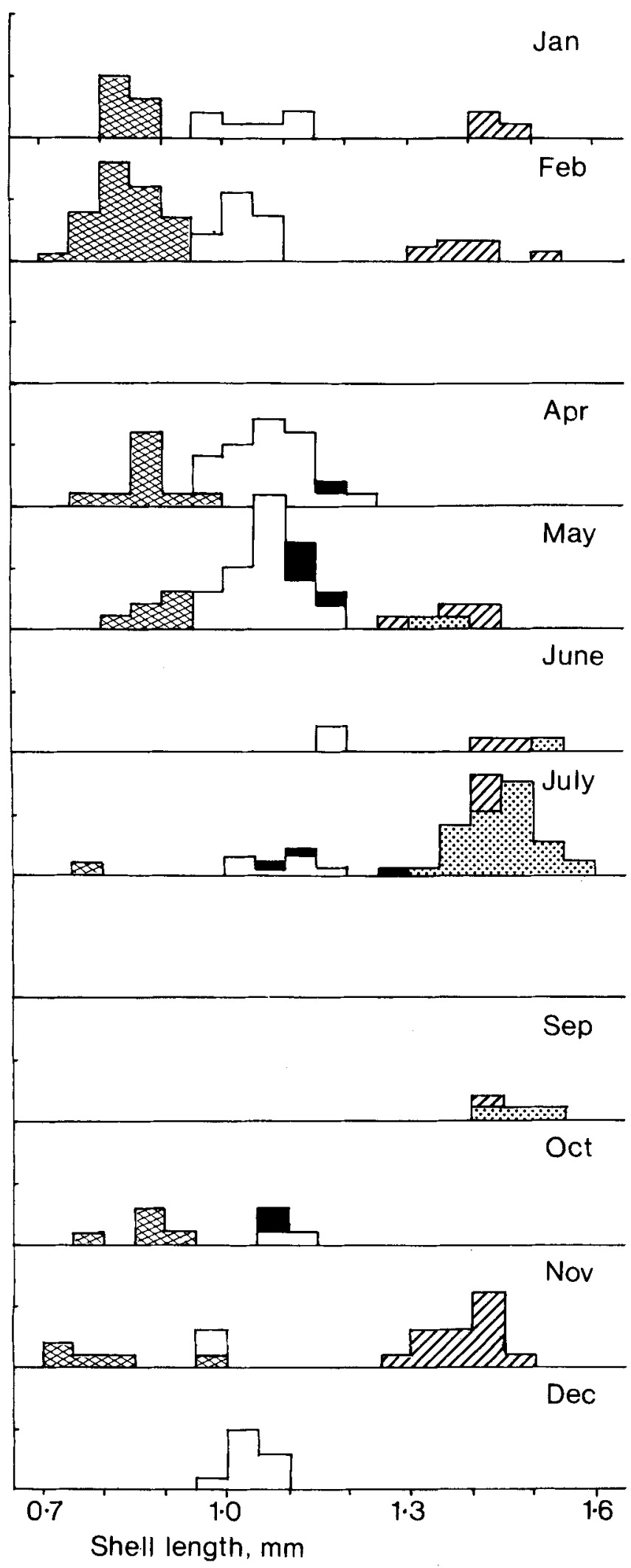

adult male presence in the population, and the low numbers of adult females early in the breeding season. At this time the ratio is approximately $1: 1$ (May - 4:3), and the subsequent decline in male numbers, attributed to post-breeding mortality, leads to a $1: 5$ ratio by July. Over all the samples, the adult sex ratio departed significantly from $1: 1\left(\mathrm{X}^{2}, \mathrm{p}<0.001\right)$.

The mean size of embryos within the brood chamber was $0.24 \mathrm{~mm}$ (range $0.21-0.27 \mathrm{~mm}$ ). The number of embryos in each brood ranged from $8-18$, with a mean of 13.4. Multiple correlation analyses (Snedecor, 1959) conducted on the data for embryo size, brood number and brooding female size (length) showed no correlation between embryo size and either of the other variables. This infers that brood density does not affect embryo growth, that there is negligible brood mortality (since numbers do not decline as embryos develop), and that larger females do not produce correspondingly larger offspring. There was a significant positive correlation between brooding female size and brood number (multiple correlation for 41 broods with embryo size partialled out: $t=5.33, p<0.001$ ). The $\log -\log$ relationship between female length $(\mathrm{L}, \mu \mathrm{m})$ and brood number $(\mathrm{B})$ is given by the regression equation: $\log _{10} B=3.1 \log _{10} \mathrm{~L}-8.71$

showing a relationship between brood size and the cube of the length, and therefore the volume of the brood chamber (Fig. 5).

The number of embryos in a brood was even significantly more often than expected by random chance ( 27 out of 41 broods even; $X^{2}=4.122$, $p<$ 0.05 ), suggesting an equal contribution from each of the paired gonads.

\section{DISCUSSION}

While the low density (a consistent feature of this species) and hence low sample numbers hinder detailed analysis of its life history, the data for $S$. zostericola at Kingsnorth demonstrate an annual life cycle, with the majority of the population overwintering as juveniles and breeding as adults the following summer. Semelparity (with death after a single breeding) has also been shown in the longer lived myodocopids Leuroleberis zealandica (Baird) (Fenwick, 1984) and Parasterope pollex Kornicker (Hulings, 1969).

All the instars studied here, while showing identical morphology to those described by Kornicker (1967)

Fig. 4. Amalgamated monthly size-frequency histograms for S. zostericola at Kingsnorth, showing instar IV (cross hatched), instar V (unshaded), adult males (black shading), adult females (diagonal shading) and brooding females (stippling). One division of the vertical axis $=10$ individuals for February and July, otherwise 5 individuals. 


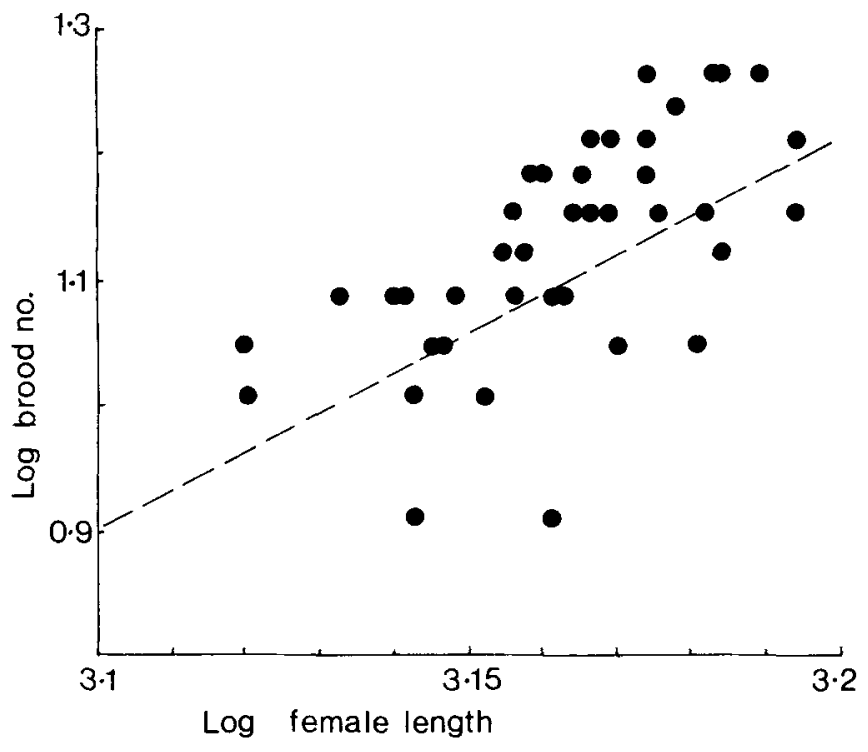

Fig. 5. Brood number plotted against female length $(\mu \mathrm{m}), \log _{10}$ scale, with regression line $y=3.1 \chi-$ 8.71 .

from North America, are significantly larger. Although the mean embryo size was smaller than Kornicker's value for Massachusetts specimens, the embryo development was not studied, and hence it is unclear what stage the means represent. The generally increased size cannot be attributed to enhanced growth in the cooling water effluent temperature: the mean temperature regime at the sample site was no higher than ambient estuary water, and was lower than the water temperatures recorded with $S$. zostericola samples in Texas (Kornicker \& Wise, 1962). The large size may be a further example of the commonly observed increase in size with increase in latitude within animal species; this trend has been observed in ostracods (see Hart \& Hart, 1979 ), and Kingsnorth is some $10^{\circ}$ of latitude further north than Kornicker's northernmost site in Massachusetts. However, there is no such trend in size within the North American data when specimens from Texas, California and Massachusettes are compared (Kornicker, 1967, fig. 1).

That Kingsnorth females carry larger broods than those in North American populations is accountable by the fact that the breeding females at Kingsnorth are larger, and larger females have been shown to have larger broods.

The overall bias of the adult sex ratio is in agreement with the findings of Kornicker (1967), with 5-7 females to each male; he also found females outnumbering males in earlier instars, though based on very small numbers of specimens. The larger numbers studied here demonstrate a 1:1 sex ratio in instars IV and $\mathrm{V}$, and, though numbers are few for the earliest adults, this ratio appears to persist through the final moult to the beginning of the breeding season, with a subsequent decline in the proportion of males. This can be simply explained by a 1:1 sex ratio in the population up to the time of breeding, after which the males die but the females necessarily persist to brood the embryos. Such a situation was concluded by Hulings (1969) for Parasterope pollex, the adult males having a life span of some eight weeks. Fenwick (1984) also found that the sex ratio in Leuroleberis zealandica only departed significantly from 1:1 in the adults (instar VII), and adult males had a shorter life span than adult females; he postulated that, in this longer lived species, the increased mobility of the males in search of mates, and thus less time spent in the substrate, probably results in increased mortality from predation, which would further contribute to the sex ratio bias.

It may be reasonably assumed that the Kingsnorth population of $S$. zostericola is a further example of introduction with North American oysters, and has therefore been established in the R. Medway Estuary for some 40 years, although Kilenyi (1969) did not record this species in his samples at Sheerness. The data from the present study confirm a successful, breeding population, and large numbers have been recorded passing through the cooling water system of the power station (see Bamber \& Spencer, 1984). Its absence from the benthic community of the discharge canal is therefore a real effect of the conditions of the effluent water. Its life history strategy, as a surface burrowing crustacean brooding a low number of minimally dispersive offspring, is not inappropriate to the conditions of the discharge canal, since the isopod Cyathura carinata (Kroyer) has a similar strategy, and lives in a dense and successful population close to the outfall of the power station (Bamber, 1985).

Both Wharfe (1975) and Bamber \& Spencer (1984) found that bivalve molluscs appear particularly susceptible to artificially heated discharges. If these observations are indicative of a real effect, relating to the physiology of shell formation or shell stability, then $S$. zostericola may experience similar problems, particularly as myodocopid shells are formed of less stable amorphous calcium carbonate (Sohn \& Kornicker, 1969).

\section{ACKNOWLEDGEMENTS}

I am grateful to Dr. Geoff Boxshall for determining the identity of $S$. zostericola, to Dr. Graham Oliver of the Department of Zoology, National Museum of Wales, for S.E.M. facilities and invaluable help, and Dr. Peter Henderson for his critical reading of this paper. This work was carried out at the Central Electricity Research Laboratories, and the paper is published by permission of the Central Electricity Generating Board. 


\section{REFERENCES}

Bamber, R. N. 1985. The autecology of Cyathura carinata (Crustacea: Isopoda) in a cooling water discharge lagoon. J. mar. biol. Ass. U.K., 65, 181-194.

Bamber, R. N. \& Spencer, J. F. 1984. The benthos of a coastal power station thermal discharge canal. J. mar. biol. Ass. U.K., 64, 603-623.

Bowen, M. 1976. Effects of a thermal effluent on the ostracods of Par Sound, South Carolina. ERDA Symp. Ser., 40, 219-226.

Fenwick, G. D. 1984. Life history and population biology of the giant ostracod Leuroleberis zealandica (Baird, 1850) (Myodocopida). J. exp. mar. Biol. Ecol., 77 (3), 255-289.

Hart, C. W. Jr \& Hart, D. G. 1979. Ostracods (Arthropoda: Crustacea: Ostracoda). In Hart, C. W. Jr. \& Fuller, S. L. H. (Eds.) Pollution Ecology of Estuarine Invertebrates, 127-144. Academic Press, London.

Hulings, N. C. 1969. The ecology of the marine Ostracoda of Hadley Harbour, Massachusetts, with special reference to the life history of Parasterope pollex Kornicker, 1967. In Neale, J. W. (Ed.) The Taxonomy, Morphology and Ecology of Recent Ostracoda, 412-422. Oliver \& Boyd, Edinburgh.

Jones, M. L. 1961. A quantitative evaluation of the benthic fauna off Point Richmond, California. Univ. California Publ. Zool., 67 (3), 219-320.

Kilenyi, T. I. 1969. The problems of ostracod ecology in the Thames Estuary. In Neale, J. W. (Ed.) The Taxonomy, Morphology and Ecology of Recent Ostracoda, 251-267. Oliver \& Boyd, Edinburgh.

Kornicker, L. S. 1967. A study of three species of Sarsiella (Ostracoda: Myodocopa). Proc. U.S. Nat. Mus., 122 (3594), 1-46.

Kornicker, L. S. 1975. Spread of ostracodes (sic) to exotic environs on transplanted oysters. Bull. Amer. Paleont., 65 (282), 129-139.

Kornicker, L. S. \& Wise, C. D. 1962. Sarsiella (Ostracoda) in Texas bays and lagoons. Crustaceana, 4, 57-74.

Langford, T. E. 1983. Electricity Generation and the Ecology of Natural Waters, 342 pp. Liverpool University Press, Liverpool.

Neale, J. W. (Ed.) 1969. The Taxonomy, Morphology and Ecology of Recent Ostracoda. Oliver \& Boyd, Edinburgh. $553 \mathrm{pp}$.

Snedecor, G. W. 1959. Statistical Methods Applied to Experiments in Agriculture and Biology, 5th edition, 534 pp. Iowa State College Press, U.S.A.

Sohn, I. G. \& Kornicker, L. S. 1969. Significance of calcareous nodules in Myodocopid ostracod carapaces. In Neale, J. W. (Ed.) The Taxonomy, Morphology and Ecology of Recent Ostracoda, 99-108. Oliver \& Boyd, Edinburgh.

Wharfe, J. R. 1975. A study of the intertidal macrofauna around the B.P. Refinery (Kent) Limited. Environmental Pollution, 9, 1-12. 